\title{
Implementation of an Innovation in Education Project in the Degree of English Studies at the University of Valencia
}

\author{
Begoña Clavel Arroitia and \\ $\mathrm{M}^{\mathrm{a}}$ Goretti Zaragoza Ninet \\ University of Valencia
}

Received: 25 November 2008 / Accepted: 23 June 2009

ISSN: $1697-7467$

\begin{abstract}
The 21st century is and surely will be characterized by multiple and dramatic changes at all levels, but especially in the field of technology. This paper examines how some of these changes influence the way in which languages in general, and English in particular, are taught nowadays. We show how we have applied an Innovation in Education Project methodology in some modules in the degree in English Studies. Our most important instrument is our E-Learning platform (Aula Virtual) which offers us numerous ways in which to bridge the gap between our students and the team of teachers and permits our students to learn through a more interactive type of methodology.
\end{abstract}

Key words: English Language Teaching, Innovation in Education Project, Aula Virtual

Implementación de un Proyecto de Innovación Educativa en la titulación de Filología Inglesa de la Universidad de Valencia

RESUMEN: El siglo XXI está y estará marcado por una serie de cambios a todos los niveles y en especial en el terreno de la innovación tecnológica. Nuestra contribución examina cómo algunos de estos cambios han influenciado la enseñanza de lenguas, y, más precisamente, de la lengua inglesa. Mostramos cómo hemos aplicado un Proyecto de Innovación Educativo en algunas asignaturas de la Licenciatura en Filología Inglesa por medio de la plataforma de enseñanza semi-presencial Aula Virtual, que nos permite salvar la distancia profesor-alumno a la vez que garantiza una metodología didáctica más interactiva.

Palabras clave: Enseñanza de la lengua inglesa, Proyecto de Innovación Educativa, Aula Virtual.

\section{INTRODUCTION}

In the following article our aim is to describe the most relevant aspects of the application of an Innovation in Education Project PIE (IEP) methodology together with the implementation of ICTs in different modules in the Degree of English Philology at the University of Valencia. We first provide an overview of the theoretical and methodological basis on which we ground 
our teaching approach. This is based on the main linguistic theories regarding the acquisition of a second language and on the teaching/acquisition of competencies.

In the third section, we consider the role of our E-learning platform, Aula Virtual, in the development of this methodology: we explain its structure and focus on how we have taken advantage of the tools it offers. More specifically, we describe the exploitation of the "Resources", "News" and "Assessment" folders. We also detail in this section the role of the "portfolio" for both teachers and students.

Finally, in the fourth section we explain how we integrate new technologies in our teaching methodology and how this brings about an improvement in the teaching-learning process.

Even though the implementation of this methodology had to overcome different obstacles, such as for instance, excessive class size, our experience was overall very positive. Two facts have been confirmed: that using a methodology that is less teacher-centred makes our modules more practical and that it improves the relationship between teacher and student.

\section{THEORETICAL FRAMEWORK}

\subsection{Theoretical principles and methodological theories}

The implementation of our methodology is based on a series of theoretical principles and methodological theories that we describe in this section. We follow Krashen (1982) and his Monitor Model in claiming that there are two differentiated processes which this author describes in the first of the hypotheses in his language acquisition model: acquisition and learning. Learning is a conscious process through which we focus on several linguistic aspects and usually takes place inside the classroom. On the other hand, the acquisition process occurs naturally and subconsciously when we receive messages that we can understand which is what he calls comprehensible input. This is a key concept in his theory since, according to Krashen, comprehensible input is the only way in which language can be acquired. Through the acquisition process, people are able to develop their first language and a second language and thus it has a crucial role in the language learning process. Therefore, this is the method we attempt to apply in class letting our students learn through a series of varied activities dealing with different topics so that they are exposed to language as much as possible, because that is the only way in which they will eventually acquire it. We could say that whereas in the classical classroom context, everything is pre-planned and controlled and the more formal aspects of language are foregrounded and learning is promoted over acquisition, through our methodology, our students would be learning language in particular and concepts in general without really noticing that they are doing so.

We can add that, according to Gee (1992), we acquire a language subconsciously by exposure to a model, through a trial and error process, and practice within social groups, normally without formal teaching. This is precisely what we want to promote through the methodology that we use. We want our students to answer questionnaires, give specific information, etc. and receive immediate feedback in their answers. These types of activities are usually related to a specific immediate context that gives the students the opportunity to acquire meaningful, real and useful knowledge which can be applied to specific functions. Our students 
can choose when and where to do these activities, thus, they will be learning without the pressure of the formal classroom context and we will be able to improve their motivation, which, together with other affective factors, is a fundamental element in their learning process. We consider that meaningful learning is a vital concept since it takes place when the student is able to select the most important information in a particular context, to organise it into a logical mental picture and to integrate the new information with existing information (Mayer, 1997).

If we take into consideration that the use of new technologies can improve the acquisition of this type of knowledge, we can then claim that, according to Mayer's (1997) Generative Theory of Multimedia Instruction, when we apply mixed modes of delivery (texts, graphics, audio, video, animation, etc.), we are proposing our students different ways of employing cognitive processes in order to acquire knowledge. Therefore, we can assert that multimedia learning takes place when our students are able to construct mental representations through words and images presented to them in a text format containing illustrations, narrations and animations. This type of learning lends weight to the hypothesis that students learn to a greater degree when the messages they receive are well-designed multimedia material than when they are exposed to more traditional types of material based only on texts. Mayer (2003) explains that an educational multimedia message is a type of presentation that includes words and images and that has been designed to foster meaningful learning. This is the type of presentations that we follow in our project: material that has been designed to contain and transmit a message, often discipline specific content, and that, at the same time, can be used to promote the type of learning that can be more beneficial for our students.

Mayer (2003) claims that students learn best when they have access to visual and verbal representations and they interact simultaneously in their memory. According to what he labels The Multimedia Effect, students can learn better from well-designed multimedia messages through which students can build mental representations from words and pictures that are presented to them than from more traditional modes of communication involving words alone.

Sweller (1999) also follows this line of research and explains that multimedia products used in the educational background can be beneficial only if they are carefully designed and do not unnecessarily overload human information processing. In this vein, in recent years, media-based listening comprehension activities have evolved from a purely audio-only approach to one that can be considered as more holistic and multi-sensory. Materials no longer focus on nonsensical sentence structures, but students now experience more authentic audio passages embedded in video, interactive CD-ROMs, or Web sites. This, together with interactive selfchecking exercises, provides them with an opportunity to examine their output in terms of recall of the target language material.

As the development of L2 multimedia increases, researchers must find out more specifically how the attributes of multimedia can enhance listening and reading comprehension and vocabulary acquisition. The increasing use of new technologies in the classroom has brought about a new teaching approach which promotes a total change in the teaching-learning process in the classroom. We have evolved from a traditional perspective based on the final product and centered on the teacher, to a model which is process-oriented and centered on the student. In this new learning model, the interaction is not only between the teacher and the student, but also between different students. This is connected to the notion of collaborative learning which posits that students learn best when they are actively involved in an activity and that students 
working in small groups tend to learn more of what is taught and retain it longer than when the same content is presented in other instructional formats. We can assert that the active exchange of ideas within small groups not only increases interest among the participants but also encourages critical thinking. This type of shared learning gives learners an opportunity to engage in discussion, take responsibility for their own learning and as a result become critical thinkers. Thus, one of the main aims of our methodology is to offer our students activities and tasks that must be tackled in groups and where negotiation, dialogue and participation should be the most important factors fostered by them.

We must promote interaction among our students, or peer interaction, which, as Toussaint Clark and I. Clark (2008) claim, is a crucial concept whose importance was already acknowledged in the 1972 convention of the International Communication Association (ICA) and has progressed extraordinarily since then. Group dynamics can act as catalyst to obtain better results in the final product of a particular task, in the interpersonal relation among students and in their psychological health.

One final important aspect to be taken into account is the fact that our students must be treated as adults and therefore we have to make them aware that they are responsible for their own learning process. As the teaching directed to children and adolescents has its own characteristics, so does teaching adults. Knowles' (1975) Andragogy Theory tries to develop a context which is specifically aimed at adult learning. This author highlights that adults are self-directed and are expected to take responsibility for the decisions they make. Therefore, we must consider those aspects when planning our methodology. We must consider that adults need to know why they need to learn something, that they need to learn experientially, that they approach learning as problem-solving and that they learn best when topics are of immediate value. This implies that instruction for adults needs to focus less on the content being taught and more on the process. Activities centred on case studies, role-playing, simulations, and selfevaluation are probably then the most useful (Morland \& Bivens, 2004). In activities of this type, according to a constructivist conception of education, the instructor adopts the role of facilitator rather than lecturer or grader, the learner becomes a constructor of meaning and technology has an influence on both roles (Sánchez Sola, 2006). The use of this kind of activities supports the problem-centred orientation required for successful adult learning and promotes task-oriented and self-directed type of strategies, which imply the application of the principles of Andragogy (Morland \& Bivens, 2004).

\subsection{Teaching competencies}

Our main objective is the students' acquisition of competencies; this is why these are incorporated in EES study plans and in our academic plans. Their introduction represents a crucial change in our educational system.

We are currently in a transition period in which we are moving from an old, traditional system which valued the accumulation of knowledge to a new one in which emphasis is on the management of learning tools and the acquisition of skills that prepare students to be autonomous and to be able to join more effectively the professional world. Therefore, the introduction of competencies in the system has acted as a link between the activities of the University and the working world, whereas for a long time the university had been accused of ignoring the market and society. For professional skills to be developed the student must be 
advised and guided by the teacher. Both teacher and student role change significantly: the teacher, a mere knowledge provider in the previous model, is now a facilitator of student competence achievement. The student is not a patient information recipient anymore, but acquires an active role becoming the architect of his/her own learning,

The Tuning project ( HYPERLINK «http://unideusto.org/tuning/» http://unideusto.org/tuning) opens with a distinction between general and specific skills. Consequently, the Libro Blanco of the Título de Grado in the area of language, literature, culture and civilization includes this classification and considers, at least, the following competencies:

1) General or cross-cultural (generic or transferable skills): skills which are necessary for employment and life as a citizen. These are important for every student no matter the subject they study. They are classified in Instrumental, Systemic and Interpersonal:

a) Instrumental (instrumental competencies): tools for learning and training, such as analysis and synthesis ability, ability to apply knowledge in practice, planning and time management, general knowledge based on the study area, basic knowledge of the profession, oral and written communication in the mother tongue, second language knowledge, basic computing skill and research skills.

b) Systemic (systemic competencies): related to the ability to learn, information management skills, capacity for self-criticism, ability to adapt to new situations, ability to generate new ideas (creativity), problem solving and decision-making.

c) Interpersonal (interpersonal competencies: knowing how to be): teamwork, personal skills, leadership, ability to communicate with non-experts in the field, appreciation of diversity and multiculturalism, knowledge of other countries cultures and customs, skill to work independently, ethical commitment, quality concern, etc.

2) Specific (subject specific): disciplinary training and skills in connection with professional profiles. These competencies have been divided into four subsections:

a) Disciplinary knowledge (to know): instrumental command of the English language, knowledge of English grammar and literature, knowledge of the techniques and methods for linguistic and literary analysis, knowledge of the linguistic variation of the English language, knowledge of the sociolinguistic situation of the English language, knowledge of history and culture of English-speaking countries, knowledge of literature in English language, instrumental command of the mother tongue, instrumental advanced knowledge of a second language.

b) Skills (knowledge): the ability to produce different kinds of texts, communication skills in oral and written English, ability to communicate and teach the acquired knowledge, ability for linguistic analysis and commentary.

c) Academic skills: the ability to receive, understand and convey the linguistic production in the languages studied, ability to identify problems and research issues and assess their relevance, and so on.

d) Other specific skills: the ability for critical thinking, creative ability, communication skills. 


\section{The INNOVATION IN EDUCATION PROJECT}

Thanks to the Innovation in Education Project (IPE), which we have been implementing for several years, the most challenging part for us teachers is to exploit the wide range of possibilities given to us by new technologies and methodologies in order to make our lessons more practical and dynamic and thus allow our students to take full advantage of the classes. Our main tool in order to do so is our E-Learning platform Aula Virtual. We take advantage of it both inside and outside the classroom and have made it an essential instrument for the implementation of our teaching methodology.

Our platform is divided into the following sections and subsections:

1. Class Home:

Class Information

News

Brief Information

Staff List

Students Cards

Schedule

Chat

2. Calendar

3. Activities

4. Communication:

Forums

FAQs

5. Information:

Educational Guide

Program of the Subject

Bibliography of the Subject

Information

6. Class Administration

We discarded the use of the chat section because we make active use of the forum and we did not want students to have too many things to do: we preferred for them to focus on a specific number of activities and demand them a high and good level of participation in those. We also discarded the use of the activities section, which has successfully been employed by other lectures in our team in other modules, because it is an appropriate tool to be used in an online environment, whereas our blended-learning methodology requires a combination of online activities and also tasks done in class which made us choose a different type of methodological approach and the use of other tools (as the resources section specifically for this purpose) as we now explain.

Aula Virtual is used principally outside the classroom. Of special importance for us are the resources folder, the news section, the self-assessment questionnaires, bulk mail, evaluation and the forum. We now discuss in detail the most important sections of our E-Learning platform. 
In the first place, we can assert that the resource folder is one of the most important and most used sections in AV. Teachers use it in order to give students feedback on any information about the course.

In the following figure we can observe the appearance of this folder once the students or teachers have had access to it:

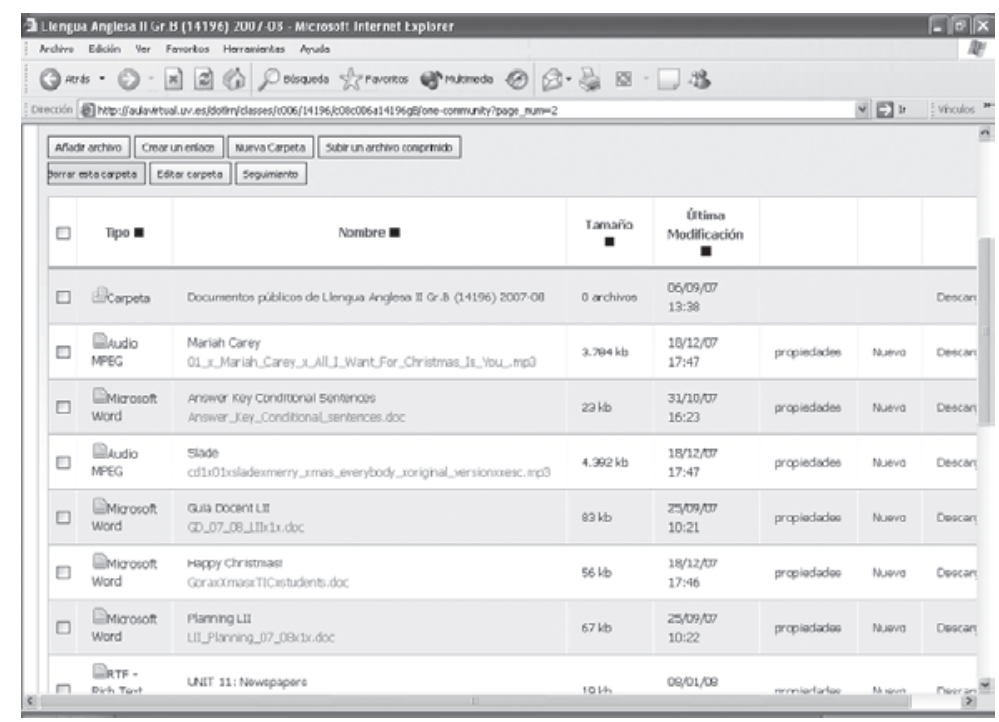

Fig. 1. The resources folder.

Through the use of this folder, students have access to the academic planning of the course (where the general planning of the lessons, contents, and exam dates are found), the teaching guide (in which students can find the syllabus of the subject, general aspects about the module, some general notions on methodology, guidelines on evaluation and related bibliography among other things), review self-correcting activities on any topic dealt with in class, read power point presentations on specific grammatical points taught in class, and in general any information that we consider important for our students to have.

In figure two we can see one of the documents in the folder. It consists of a series of review activities which deal with grammatical aspects which have been explained and worked on in class previously in greater depth. We expect our students to work on them on their own and in some of the cases they can add those activities to the work load expected to be carried out and handed in their portfolio. It is essential for us that students consolidate and practice the contents that have been introduced in class. As we use a communicative approach in our teaching, and thus use group work in the classroom, sometimes students are expected to work individually at home. 


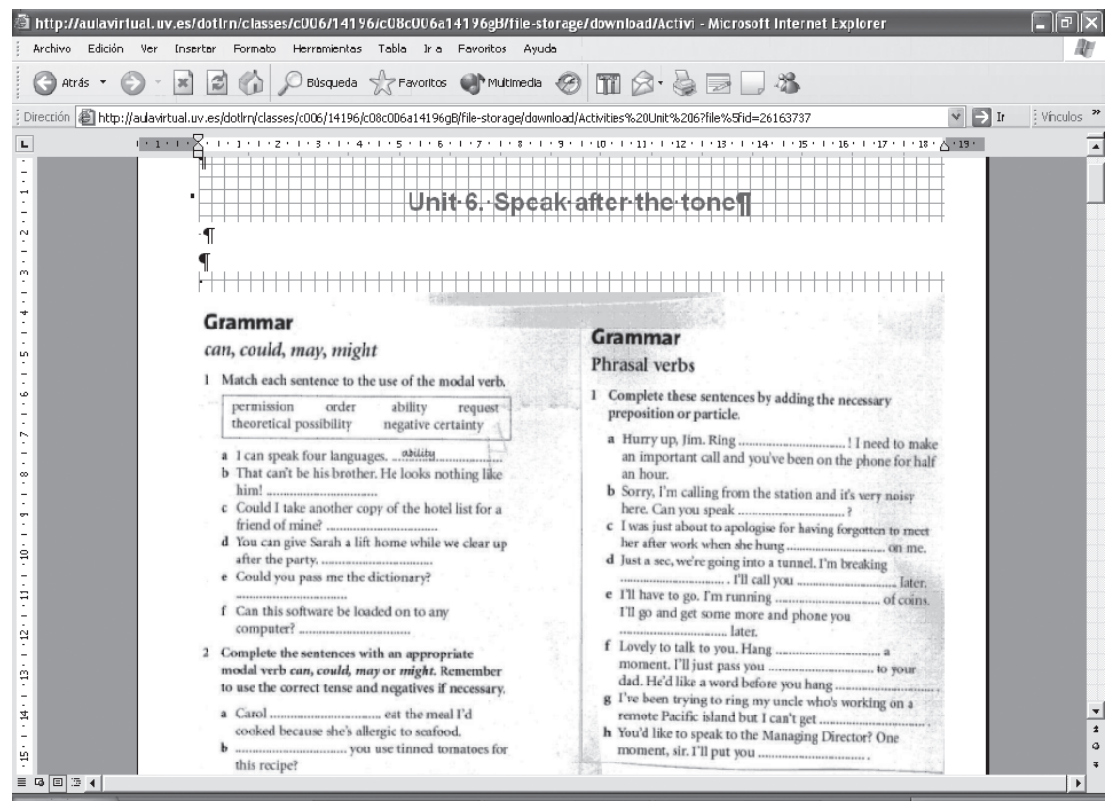

Fig. 2: Self-assessment activities on one of the units.

In the resources folder we also upload activities which have been done in class but that some students missed or which others may prefer to do again. That is the case of songs, for example, which students can use as a listening activity, but also as a reading comprehension exercise or as a topic on which to write a composition. We usually work with these types of activities at specific times of the year such as Christmas:

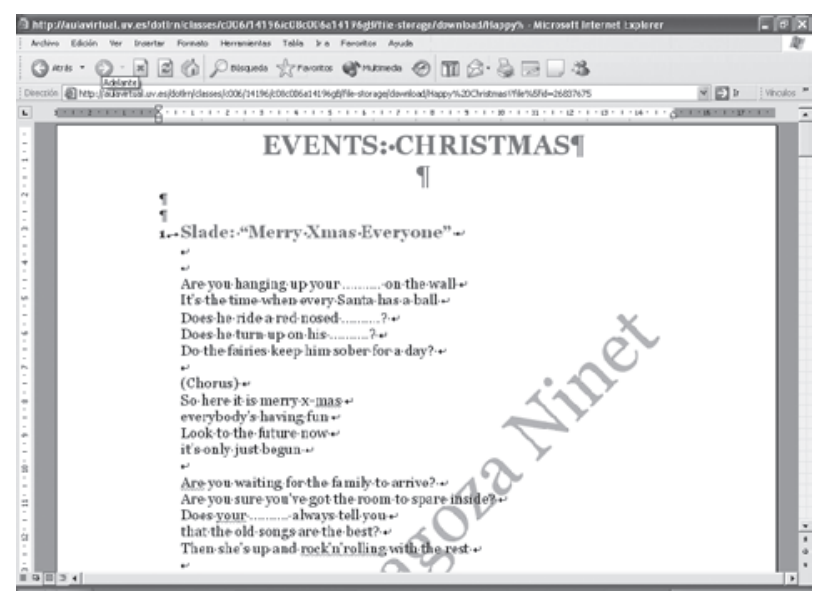

Fig. 3: Multimedia activity. 
Another important section for us in AV is the self-assessment questionnaires. It is important for students to practice and automatize what they have learned in class. As we stated before, conscious learning is an important part of the teaching-learning process, but the unconscious process of acquisition is equally important and complementary and it can only be reached through repeated practice and through exposure to input. One of the ways to do so is the use of these types of questionnaires, with which students can work individually and at their own pace and they can check their answers and learn from their mistakes. They have several questionnaires on the important grammar points dealt with during the course and the teachers can check when they did them, how much time they devoted to them, how many times they tried, and their final result. Here we offer an example of one of these activities:

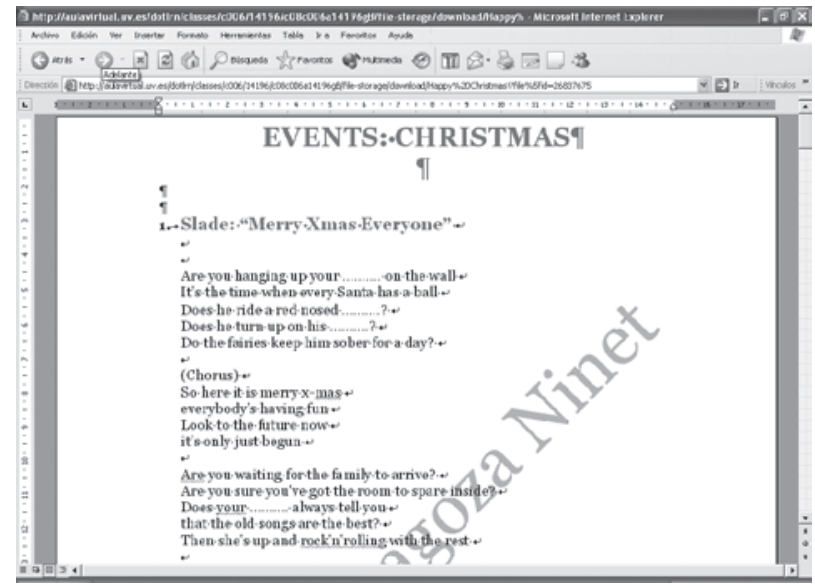

Fig. 4: Questionnaire on phrasal verbs.

Of special importance for us are the bulk mail and news section: they are our main tools with which to communicate with our students. We can inform them about any change in the usual schedule for lessons, about any new documents that have been uploaded to the resources folder, about any activity taking place at university or elsewhere and that we find interesting for them. We can also remind them about important events such as exam dates, portfolio dates, etc. We need to be in contact with them constantly and this facilitates the interaction not only between the teacher and the students, but also among the different teachers of the subject. We now offer two examples of these two sections: 


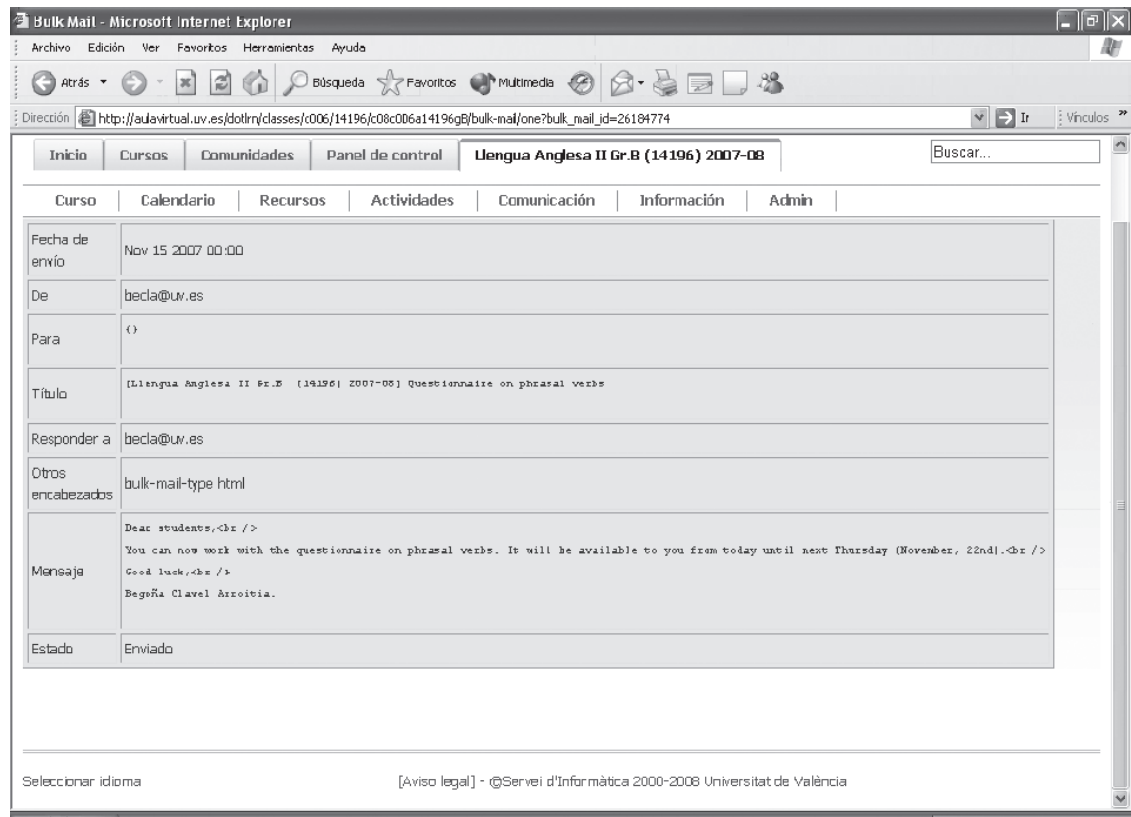

Fig. 5: Example of an e-mail sent to all the students.

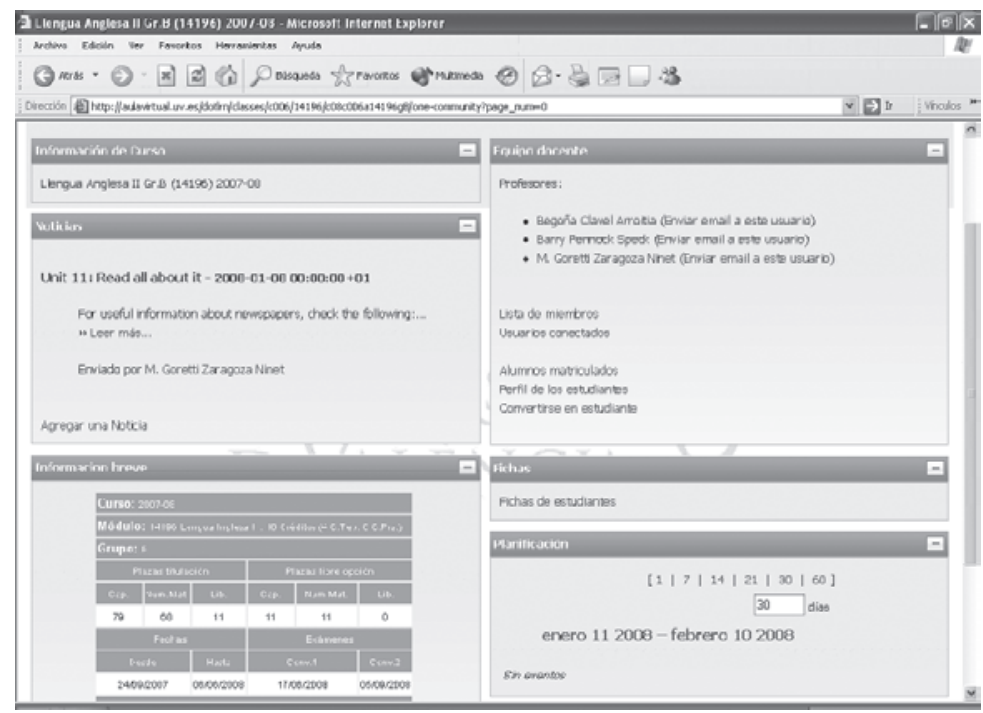

Fig. 6: News section in Aula Virtual 
Finally we describe the last relevant part of our E-Learning platform: An important section in our methodology is the portfolio. We want our students to work by themselves and consolidate the contents that have been dealt with in class from a theoretical standpoint. It is not a completely electronic portfolio as it is in the case of other modules in the same degree since we want our students to work on a wide range of different activities, some of them online, but others done with the help of coursebooks, grammar books, group work, pair work, etc. and we want them to put all that material together at the end of the year and hand it in to us during a personal interview. In the different modules, we ask them to do different projects or work with a self-study grammar book, among other activities, and this allows them to review all the important concepts in a theoretical way and at the same time it offers a series of exercises that can help them practice the important points that they need to know. Once or twice a year, depending on the module, they come to our office and hand in the work they have done. As stated above, practice of theoretical aspects is crucial in the automatizing of concepts if we want our students to acquire the target language. In the resources folder in Aula Virtual, students can access a document explaining the guidelines on the handing in of their portfolio:

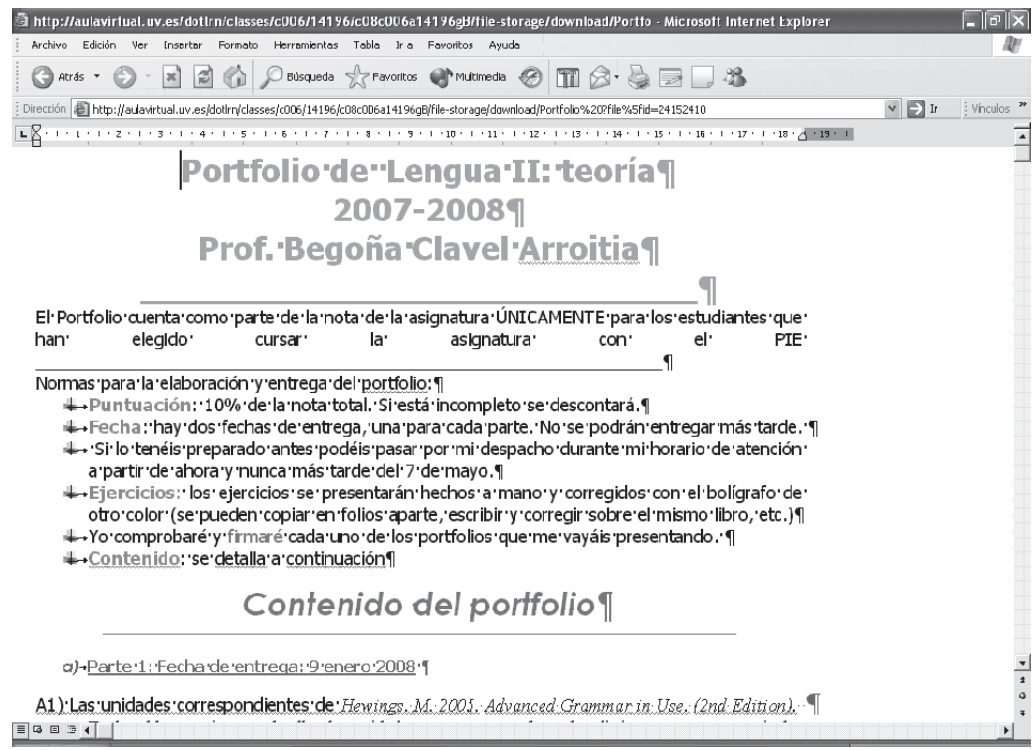

Fig. 7: Portfolio in the resources folder.

This interview allows us to have personal contact with them which offers us the opportunity to obtain feedback from students on the course in general or on specific aspects of the module in particular.

We can finally state that Aula Virtual can be considered as our main tool in order to improve our communication and interaction with students outside the classroom and it has served as catalyst of the interaction between teachers and students. 


\section{ICT INTEGRATION IN THE TEACHING METHODOLOGY}

We have also incorporated ICT in the teaching methodology, enabled, partly, by the project: "Diseño y creación de materiales multimedia y profundización en la enseñanza semipresencial", sponsored by the University of Valencia in which we take part. Firstly, we have made use of ICT: the theoretical lectures were given through the medium of power point presentations and the students have in turn, employed this programme in order to prepare and deliver their presentations. Furthermore, we have made use of other software in order to elaborate online self-corrected questionnaires, namely, Respondus (HYPERLINK «http:// www.respondus.com/download/index.shtml» http://www.respondus.com/download/index.shtml). The questionnaires are first created in Word with a specific format and are then transferred to the programme to convert them into real online questionnaires. Finally, these are uploaded to the e-learning platform. Other software, specifically Audacity (HYPERLINK «http:// audacity.sourceforge.net/download» http://audacity.sourceforge.net/download), helps us work with the different audio files in order to create audio questionnaires, of particular relevance in the subject of dialectology. Besides all this, in the lectures we have exploited a wide range of audio and video material including films, series, TV shows, real audio files, video extracts, etc., which were aimed not only at developing students' listening comprehension skills and grasp of the different English accents and dialects, but also at making lectures more dynamic and entertaining.

We try to exploit all the technological resources available for us at the moment in order to make our lessons more dynamic and interactive. Students need to be exposed to input and they also need to produce some output in order to automatize the language and activities of this type are a good means to do so.

As Kupelian (2001) claims, the use of technological resources in the L2 classroom has three main advantages: it reduces student anxiety, it becomes a strong motivator and implies an improvement in language skills. The importance of using online activities in order to augment intellectual activities is also mentioned by other authors, as Harasim (1990) who claims that they can promote active learning and knowledge building since they stimulate crucial educational processes as idea generating, idea linking and idea structuring.

It is useful when implementing new technologies to focus on the empirical evaluation of the methodology in order to know if our students have indeed benefited from it. Chapelle (1998) offers a series of hypothesis or ideal conditions for second language acquisition in the context of multimedia instruction. She mentions the following:

1. Making key linguistic characteristics salient.

2. Offering modifications of linguistic input.

3. Providing opportunities for "comprehensible output."

4. Providing opportunities for learners to notice errors.

5. Providing opportunities for learners to correct their linguistic output.

6. Supporting modified interaction between the learner and the computer.

7. Acting as a participant in L2 tasks.

They can be used as a guideline when designing one's project or as a means of evaluating one's methodology. We have considered them to evaluate our methodological approach and they have been useful for us to know which specific points need improvement. We realised 
that, for instance, we do make key linguistic characteristics salient by highlighting them in power point presentations, for example; we also offer opportunities for our learners to request modifications when we present input in multimedia material; we give them the chance to produce output that may stretch their competence and we give them tasks that focus the learners' attention and are designed to accomplish a goal through the use of language. On the other hand, we need to work more on creating activities that promote more the fourth, fifth, and sixth conditions, as the processes of noticing errors, self-correcting and supporting modified interaction between the learner and the computer are crucial factors in the acquisition of a second language.

\subsection{The Sing a Song, Learn Along Project}

We are going to focus our attention on a specific project designed for the module of English Language II, but also used in a cross-curricular way in other modules in the degree. Apart from exploiting our e-learning platform and using activities designed to be used in the classroom, we have created a specific web-based project called Sing a Song, Learn along (Clavel and Zaragoza, 2008).

Our aim was to create extra material for the students of English Language. However, due to the cross-curricular nature of the material, it can be also used in subjects such as English Dialectology, History and Culture, Phonology and others. The site revolves around different songs for which we have created a series of activities. We chose classic pop/rock songs as they are less ephemeral than the latest top-twenty hits; songs that deal with broad topics which refer to cultural and historical aspects that were relevant at the time they happened but could also be applied to today's society. They include an issue that affects all human kind (A Hard Rain's A-Gonna Fall), socio-cultural legacy (American Pie), a historical and cultural moment in the history of a specific country (Sunday Bloody Sunday), or problems arising from consumerism, conforming or lack of fight (Pretty Fly for a White Guy). This is just the first selection of songs and in further stages we plan to include songs that centre on other topics such as love, war, friendship, etc.

The type of activities created around the songs include more traditional activities, such as vocabulary, grammar, translation and writing, and also multimedia activities, such as web quests, video, audio, etc. Both types of activities can be answered on line using the tools of our e-learning platform. The material was designed in order to be exploited on-line, as traditional tasks (use of downloadable handouts and photocopies) and as blended learning tasks (some activities in the classroom and others as autonomous work). Both teachers and students can use the material in these three ways. Our e-learning platform (Aula Virtual) is essential for this project, specially the Multimedia Server which allows us to upload the songs and the necessary material. 


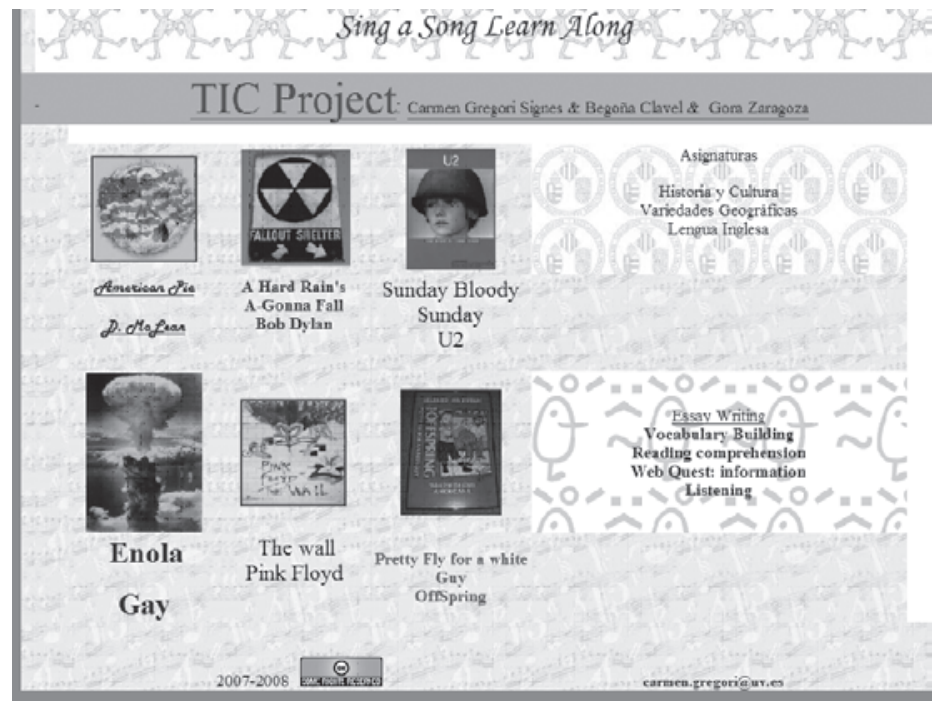

Fig. 8. Sing a Song, Learn Along.

\subsection{Competence Integration}

Another change brought about by the IEP methodology is the defence of a cross-cultural teaching method: for example, English Dialectology, among other modules, has given the students the opportunity to practice the four competencies which make up the communicative competence of any second language speaker (Canale and Swain 1980). Therefore, the students have improved their grammatical competence (words and rules) through reading articles and through the creation of power point team presentations and their accompanying written handouts. Moreover, their sociolinguistic competence (appropriateness) has been exercised through a study of the different registers associated with the different varieties of English. Discourse competence (cohesion and coherence, attention to the reader's needs) was highlighted both during the making of their presentations and the written handouts aimed at providing students with written summaries of every presentation. Finally, we tried to ensure the strategic competence (appropriate use of communication strategies) through the oral delivery of presentations. All in all, as the focus is on the delivering content, the students were less aware that they were using a foreign language and more concerned with getting their ideas across which, we hope, fostered the acquisition of English vocabulary, structures, pronunciation and prosody.

We can claim that the IEP implemented in several of the modules taught in the degree has been a useful tool in the development of additional student competencies and skills. For instance, students' team presentations have helped acquire interpersonal competencies -such as critical and respectful attitudes towards other students and their opinions- and systemic competencies -autonomous learning, summarising skills and the transmission of ideas. Besides, learning to use questionnaires, Aula Virtual and other software has proved useful in the building up of technical or instrumental competencies, such as using computers and audio and 
video material; finally, the final test has facilitated the teaching of disciplinary and academic competencies -such as aptitude for oral communication- and professional skills, such as being able to identify problems and select research topics.

\section{Conclusions}

The implementation of the methodologies which are part and parcel of the IEP has brought about radical changes in our teaching and the way students learn/acquire content and competencies. We have made extensive use of ICT inside and outside the classroom; we have used our e-learning platform extensively as an essential tool within our methodological approach and we have promoted the use of different types of activities so as to change class dynamics in general. This has meant a change in approach, from a teacher-centred one to numerous and different types of interaction : teacher to a single student, teacher to a group of students, student to student, student to a group of students and a group of students to another group. This new style of class dynamics gives students the opportunity to participate, negotiate, discuss, give opinions and develop many other types of competencies which we find essential for the learning process and which did not exist before the introduction of IEP methodology. Furthermore, the implementation of the Innovation in Education Project has strengthened teacher-student contact and promoted students' class attendance, having 60 students on average per class.

With the implementation of the IEP and the ICT Projects, we have attempted to promote a learning process that does not end once the lecture is finished, but goes on through the medium of online activities permitting the students to be in permanent contact both with the subject and with the English language. As to the assessment processes, traditionally, some of the modules in the degree used to be difficult subjects consisting of only one examination at the end of the year, whereas at present, individual and group work is assessed which makes the process a more feasible and engaging one. As an example, in English Dialectology, the change has been very promising. Out of 110 students, 72 (65\%) chose this type of methodology and no student failed the module.

\section{Bibliographical References}

Canale, M. and Swain, M. (1980). "Theoretical bases of communicative approaches to second language teaching and testing". Applied Linguistics 1: 1-47.

Chapelle, C.A. (1998). "Multimedia CALL: Lessons to Be Learned from Research on Instructed SLA." Language Learning \& Technology 2/1: 22-34.

Clavel Arroitia, B. and M ${ }^{a}$ G. Zaragoza Ninet (2008). "Teaching English in the 21st century". Proceedings of the International Association of Technology, Education and Development (IATED) 2008.

Gee, J.P. (1992). The Social Mind: Language, Ideology and Social Practice. New York: Bergin \& Garvey.

Knowles, M. (1975). Self-Directed Learning. Chicago: Follet. 
Krashen, S. (1982). Principles and Practice in Second Language Acquisition. New York: Pergamon Press.

Kupelian, M. (2001) "The Use of E-mail in the L2 Classroom: An Overview." Second Language Learning \& Teaching 1. Retrieved October, 2008 from the World Wide Web: HYPERLINK «http://www.usq.edu.au/users/sonjb/sllt/1/Kupelian01.htm» http://www.usq.edu.au/users/sonjb/ sllt/1/Kupelian01.htm

Harasim, L.M. (Ed.) (1990). Online Education: Perspectives on a New Environment. New York, NY: Praeger.

Mayer, R. (1997). "Multimedia learning: Are we asking the right questions?" Educational Psychologist $32 / 1: 1-19$.

Mayer, R. (2003). "The promise of multimedia learning: using the same instructional design methods across different media." Learning and Instruction 13 /2: 125-139.

Morland, D. V. and H.L. Bivens (2004). "Designing Instructional Articles in Online Courses for Adult Learners." Innovate Journal of Online Education 1/ 2. Retrieved October, 2008 from the World Wide Web: HYPERLINK «http://roi-learning.com/papers/ Designing_Online_Courses-Morland-Bivens-2004.pdf» http://roi-learning.com/papers/ Designing Online Courses-Morland-Bivens-2004.pdf

Sánchez Sola, A. (2006). "El Uso de las Plataformas Telemáticas en las Clases Presenciales de Lengua: El Internet Classroom Assistant (ICA).” HYPERLINK «http://espiral.xtec.net/jornada2006/je06_asanchez.pdf» http://espiral.xtec.net/jornada2006/je06_asanchez.pdf

Sweller, J. (1999). Instructional design in technological areas. ACER Press. Camberwell, Australia.

Toussaint Clark, C. and I. Clark. (2008). "Exploring and Exposing the Gap in L2 Research: How Socio-Linguistic Roles and Relationships Facilitate or Frustrate Second Language Acquisition". Atlantis. Journal of the Association of Anglo-American Studies 30 /1: 101-113. 